\title{
Unilateral Adrenal Hyperplasia: A Rare Cause of Primary Aldosteronism
}

\author{
M. Noor Ezmas ${ }^{a}$, M. Rohaizak ${ }^{b}$, AS. Nordashimac, Y. Yazmin ${ }^{d}$ \\ ${ }^{a}$ Department of Surgery, Kulliyyah of Medicine, International Islamic University Malaysia, Kuantan, Pahang, Malaysia. \\ ${ }^{b}$ Department of Surgery, Faculty of Medicine, Universiti Kebangsaan Malaysia, Kuala Lumpur, Malaysia \\ 'Department of Pathology, Faculty of Medicine, Universiti Kebangsaan Malaysia, Kuala Lumpur, Malaysia \\ ${ }^{d}$ Department of Radiology, Faculty of Medicine, Universiti Kebangsaan Malaysia, Kuala Lumpur, Malaysia
}

\section{ABSTRACT}

A 73-year-old gentleman with a background history of long-standing hypertension and hyperlipidaemia presented with one-year history of persistent asymptomatic hypokalaemia associated with metabolic alkalosis. Within a few months, the hypertension worsened, needing increasing dose of anti-hypertensive agents. Biochemical test showed an elevated aldosterone-renin ratio but the computerized tomography (CT) scan of adrenal did not show any adrenal mass. Arterial stimulation venous sampling (ASVS) lateralized the lesion to the left side. A left retroperitoneal adrenalectomy was performed with immediate reversal of hypokalaemia and improvement of blood pressure control to only single anti-hypertensive agent.

KEYWORDS: primary aldosteronism, adrenal venous sampling, adrenal hyperplasia, hypertension

\section{INTRODUCTION}

Primary aldosteronism (PA) is characterised by aldosterone hypersecretion and represents a common cause of secondary hypertension. It accounts for $5-10 \%$ of hypertensive patients. ${ }^{1}$ The incidence is underreported perhaps due to difficulty in the screening tool, as the Aldosterone-Renin ratio (ARR) has a lot of heterogeneity in terms of result interpretation and laboratory protocol. During diagnostic evaluation, it is important to determine the aetiology of PA since the treatment of unilateral and bilateral disease differs significantly. In patients with proven unilateral overproduction of aldosterone, unilateral adrenalectomy is curative and preferred over medical therapy.

\section{CASE REPORT}

A 73-year-old man had a ten-years history of hypertension and hyperlipidaemia, requiring only single

Corresponding Author:

Prof. Dr. Rohaizak Muhammad

Department of Surgery, Faculty of Medicine,

Universiti Kebangsaan Malaysia,

56000 Cheras, Kuala Lumpur, Malaysia.

Tel No: +03-9145 8240

E-mail : rohaizak@hotmail.com anti-hypertensive and lipid lowering agent with good control of blood pressure. He presented a year ago with persistent significant hypokalaemia of $2.4 \mathrm{mmol} / \mathrm{L}$ (3.5 $5.1 \mathrm{mmol} / \mathrm{L}$ ) and metabolic alkalosis. It was incidentally detected during blood screening prior to cardiac stress test for moderate risk stratification. Subsequently, he developed resistant hypertension, needing three antihypertensive agents. He was screened for plasma aldosterone and renin activity which showed elevated plasma aldosterone of $669.5 \mathrm{pg} / \mathrm{mL}$ with low plasma renin activity of less than $0.2 \mathrm{ng} / \mathrm{mL} / \mathrm{hr}$. The Aldosterone-Renin ratio (ARR) was high (> 334), suggestive of primary aldosteronism. In view of the spontaneous hypokalaemia with significant high plasma aldosterone $>200 \mathrm{pg} / \mathrm{mL}$ and supressed renin, confirmatory test was not needed. Computed tomography (CT) of the adrenal failed to show any obvious lesion and this was proceeded with venous sampling. The result is shown in Table 1 which lateralised the lesion to the left adrenal gland.

Despite the CT scan not showing any nodules, in view of convincing lateralization test, a left retroperitoneal adrenalectomy was performed uneventfully. 
Table 1: Result of arterial stimulation venous sampling

\begin{tabular}{lccccc}
\hline & $\begin{array}{c}\text { Cortisol } \\
\text { nmol/L }\end{array}$ & $\begin{array}{c}\text { Aldosteron } \\
\text { e pg/ml }\end{array}$ & $\begin{array}{c}\text { Cortisol } \\
\text { (Adrenal } \\
\text { vein: } \\
\text { peripheral) }\end{array}$ & $\begin{array}{c}\text { Aldosterone: } \\
\text { Cortisol } \\
\text { ratio }\end{array}$ & $\begin{array}{c}\text { Lateralization index } \\
\text { (Aldosterone Cortisol ratio } \\
\text { adrenal vein: Peripheral) }\end{array}$ \\
\hline $\begin{array}{l}\text { Left adrenal } \\
\text { vein }\end{array}$ & 420 & 2511 & 1.72 & 5.97 & 4.776 \\
$\begin{array}{l}\text { Right adrenal } \\
\text { vein }\end{array}$ & 474 & 241 & 2.75 & 0.51 & 0.405 \\
$\begin{array}{l}\text { Left } \\
\text { peripheral }\end{array}$ & 244 & 306 & - & 1.25 & - \\
$\begin{array}{l}\text { Right } \\
\text { peripheral }\end{array}$ & 172 & 217 & - & 1.26 & - \\
\hline
\end{tabular}

Post-operatively, the blood pressure became better controlled with only single anti-hypertensive agent and potassium reverted to normal; $4.5 \mathrm{mmol} / \mathrm{l}$ (3.5 - 5.1 $\mathrm{mmol} / \mathrm{L})$ without any supplement or potassium sparing anti-hypertensive agent. Histopathology report showed marked expansion of zona fasciculata and reticularis, consistent with a unilateral adrenocortical hyperplasia (Figures 1 \& 2). A repeat test post-operatively showed serum aldosterone of $59.45 \mathrm{pg} / \mathrm{ml}$ and plasma renin of $0.326 \mathrm{ng} / \mathrm{mL} / \mathrm{hr}$ giving ARR of 18.2 .

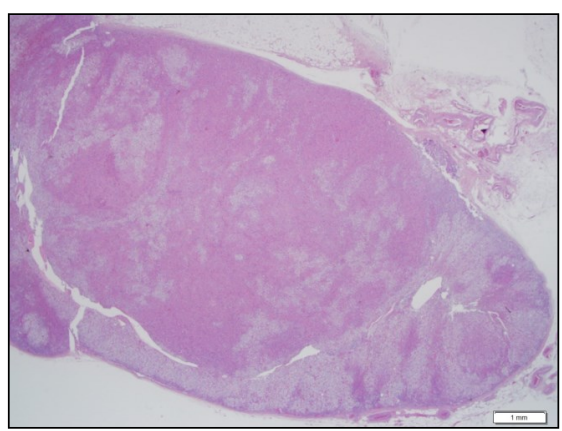

Figure 1: Microscopic appearance of the resected adrenal gland showing diffuse hyperplasia with micronodular formation. Hematoxylin and Eosin stain. (H\&E stain. Magnification $\mathrm{x} 4)$.

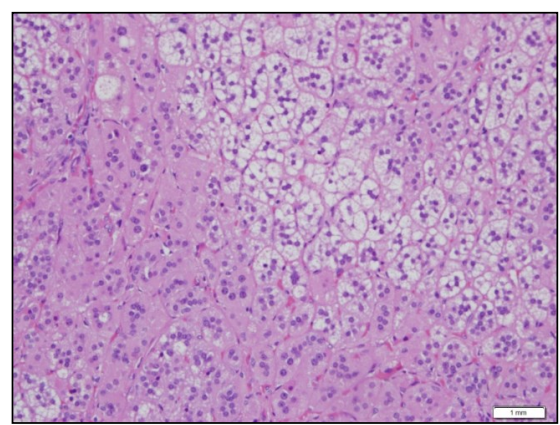

Figure 2: Marked expansion of zona fasciculate and reticularis. One population is fasciculate-type cells exhibiting nests of cortical cells with round hyperchromatic nuclei, inconspicuous nuclei and abundant pale cytoplasm (white arrow). Another population is reticularis-type cells exhibiting polygonal cell with round vesicular nuclei (black arrow). (H\&E stain, Magnification $\mathrm{x} 40$ )

\section{DISCUSSION}

Based on the latest European and American guidelines, resistant hypertension is defined as high blood pressure that remains above goal with the use of 3 or more antihypertensive agents. ${ }^{1}$ Our patient has long standing hypertension but only started to develop resistant hypertension at the age of 73 , which is relatively uncommon. Thus, the evaluation of resistant hypertension requires investigation to identify and treat the secondary causes of hypertension, including primary aldosteronism, obstructive sleep apnoea and renal artery stenosis. ${ }^{1}$

The approach to diagnosing primary hyperaldosteronism should be step-wise, starting with screening of at-risk populations, confirmatory testing for positively screened patients, and subtype classification in order to plan for surgical or medical management. ${ }^{2}$ In the case presented, it was an opportunistic screening where he was referred following routine blood test for unexplained persistent hypokalaemia needing fast correction of potassium. Only then was he screened for primary aldosteronism and ruled out for other causes of secondary hypertension. The confirmatory test was not needed in this case as it fulfilled the criteria of case confirmation which were spontaneous hypokalaemia, marked high plasma aldosterone concentration $>20 \mathrm{ng} / \mathrm{dL}$ and supressed plasma renin.

Based on current guidelines, subtype classification of primary hyperaldosteronism should be determined with both imaging and adrenal vein sampling (AVS), reserving deferment of AVS for a selective subset of patients $.3,4$ AVS is the gold standard diagnostic test for 
surgically curable primary aldosteronism. However, it is invasive, technically challenging and difficult to interpret. Due to AVS complexity, costs and limited availability, many patients with PA are being treated based on the computed tomography (CT) findings.

A non-functioning adrenocortical adenoma is not uncommon. Hence, cases of discrepancies between CT and AVS results have been widely reported, thus demonstrating the need of arterial stimulation venous sampling (ASVS) for localising the source of aldosterone excess. 3,5,6 Based on Wachtel et al, primary aldosteronism patients with non-localizing imaging but lateralizing AVS would definitely benefit from adrenalectomy $^{7}$ as seen in the case presented. Regardless of imaging findings, AVS is indicated to determine whether patients may be surgically curable. Thus, a correct subtype diagnosis will determine whether the patient may be surgically curable. It is also seen as a practical treatment objective to reduce the risk associated with cardiovascular disease. 8,9

Unilateral adrenalectomy will remove the source of aldosterone and treat the hypokalaemia. Unfortunately, the hypertensive changes in the kidney may not be completely reversible but the control of hypertension might be improved. Based on a retrospective cohort study for unilateral adrenalectomy for PA from 2004 to 2015 by Shariq et al, all patients achieved biochemical normality following adrenalectomy. There was no significant difference in the rates of hypertension cure or improvement observed in comparisons across pathological subtype.10 From 206 patients who met the inclusion criteria, $152(73.8 \%)$ had single adenoma, 33 $(16 \%)$ had unilateral hyperplasia, and 21 (10.2\%) had multiple unilateral adenomas. Those with unilateral hyperplasia were more likely to be male $(81.2 \%$ vs $57.9 \%, \mathrm{P}=.03)$ and tend to be on the left side $(78.8 \%$ vs $47.4 \%, \mathrm{P}<.01)$ as in the case presented. Unilateral adrenalectomy performed either laparoscopically or retroperitoneoscopically is generally safe, efficient and curative in primary aldosteronism with resistant hypertension. 8,10

\section{SUMMARY}

Unilateral adrenal hyperplasia is a rare cause of resistant hypertension. Lateralization of the disease by arterial stimulation venous sampling is essential before surgery.

Outcome of surgical treatment is excellent following appropriate diagnosis.

\section{REFERENCES}

1. Grassi G, Calhoun DA, Mancia G, Carey RM. Resistant Hypertension Management: Comparison of the 2017 American and 2018 European High Blood Pressure Guidelines. Curr Hypertens Rep. 2019:21(9);67

2. Young WF. Diagnosis and treatment of primary aldosteronism: practical clinical perspectives. Journal of Internal Medicine. 2019:285(2);126-148

3. Leksic G, Alduk AM, Molnar V, Haxhiu A, Haxhiu A, Balasko A, Knezevic N, Dusek T, Kastelan D. Computed tomography scan can be misleading in the lateralisation of aldosterone excess. Endocrinology, diabetes \& metabolism case reports. 2019:2019(1);19-0018.

4. Wachtel H, Salman MD, Zaheer MD, Parth K. Shah MD, et al. Role of adrenal vein sampling in primary aldosteronism: Impact of imaging, localization, and age. J Surg Oncol. 2016;113 (5):532-7

5. Rossi GP, Mulatero P, Satoh F. 10 good reasons why adrenal vein sampling is the preferred method for referring primary aldosteronism patients for adrenalectomy. Journal of hypertension. 2019:37 (3);603-611

6. Campbell RA, Young DS, Shaver CN, Lairmore TC, McDonald DK. Influence of Adrenal Venous Sampling on Management in Patients with Primary Aldosteronism Independent of Lateralization on Cross-Sectional Imaging. Journal of the American College of Surgeon. 2019: 229(1);116-124

7. Wachtel H, Bhandari S, Roses RE, Trerotola SO, Fraker DL. Primary aldosteronism with nonlocalizing imaging. Surgery. 2019:165(1);211-218

8. Hundemer GL, Vaidya A. Primary Aldosteronism Diagnosis and Management: A Clinical Approach. Endocrinol Metab Clin North Am. 2019;48(4):681700

9. Yozamp N, Vaidya. The prevalence of primary aldosteronism and evolving approaches for treatment (Review). Current Opinion in Endocrine and Metabolic Research. 2019:8;30-39 
10. Shariq OA, Mehta K, Thompson GB, Lyden ML, Farley DR, et al. T.J. Primary Aldosteronism: Does Underlying Pathology Impact Clinical Presentation and Outcomes Following Unilateral

Adrenalectomy? World Journal of Surgery. 2019:43 (10);2469-2476 